\title{
Use of Automated Bolus Calculators for Diabetes Management
}

\author{
Frank L Schwartz, MD, FACE ${ }^{1}$ and Cynthia R Marling, PhD² \\ 1. Professor of Endocrinology, The Diabetes Institute, Ohio University Heritage College of Osteopathic Medicine, Athens, Ohio, Us; \\ 2. Associate Professor, School of Electrical Engineering and Computer Science, Russ College of Engineering and Technology, Ohio University, Athens, Ohio, US
}

\begin{abstract}
Less than $30 \%$ of patients with diabetes who are on insulin therapy achieve target glycated hemoglobin (HbA $\left.{ }_{1 c}\right)$ levels. Automated bolus calculators (ABCs) are now almost universally used for patients on insulin pump therapy to calculate pre-meal insulin doses. Use of ABCs in glucose monitors and smart phone applications have the potential to improve glucose control in a larger population of individuals with diabetes on insulin therapy by overcoming the fear of hypoglycemia and assisting those with low numeracy skills.
\end{abstract}

\section{Keywords}

Automated bolus calculators, glucose algorithms, blood glucose measurement, continuous glucose monitoring, glycemic control

Disclosure: The software and methodology implemented in the 4 Diabetes Support System have been submitted to the US patent office, application number US60/901,703, and rights are co-owned by the Ohio University Technology Transfer Office, Cynthia R Marling, PhD, and Frank L Schwartz, MD, FACE.

Acknowledgments: The authors gratefully acknowledge the following sources of funding: National Science Foundation, Medtronic, Ohio University Russ College Biomedical Engineering Fund, JO Watson, DO Endowed Diabetes Research Chair of the Osteopathic Heritage Foundation, Ohio University Heritage College of Osteopathic Medicine Research and Scholarly Affairs Committee, and the Ohio University Diabetes Research Initiative.

Received: July 11, 2013 Accepted: July 25, 2013 Citation: US Endocrinology, 2013;9(2):124-7 DOI: 10.17925/USE.2013.09.02.124

Correspondence: Frank L Schwartz, MD, FACE, Professor of Endocrinology, JO Watson Chair for Diabetes Research, The Diabetes Institute, Ohio University Heritage College of Osteopathic Medicine, 331 Academic Research Center, Athens, OH 45701, US. E: schwartf@ohio.edu

\section{Automated Bolus Calculators}

Insulin dosing algorithms have been used for years by healthcare providers to improve glucose control in patients with diabetes. With the development of insulin pumps and their increased use in the early 1980s, and with the publication of the results from the Diabetes Control and Complications Trial (DCCT) in the early 1990s demonstrating the benefits of intensive glucose control in preventing the long-term complications of diabetes, both the capacity and need to achieve intensive glucose control occurred. ${ }^{1-4}$

The first technology to assist patients in calculating meal insulin boluses, which was developed to improve postprandial glucose control, was in a personal digital assistant (PDA), reported by Gross et al. ${ }^{5}$ in 2003 . This became the prototype for the meal 'bolus wizard' developed by Medtronic MiniMed (Northridge, California) for use in their insulin pumps. Currently, all commercially available insulin pumps have some form of automated bolus calculator $(A B C)$ algorithm software built into them, although the parameters for each $A B C$ vary. ${ }^{\circ}$

Over the last few years, ABCs (e.g. ACCU-CHEK ${ }^{\circledR}$ Aviva Expert ${ }^{\circledR}$ and Freestyle InsuLinx ${ }^{\circledR}$ Blood Glucose Monitoring System) have had glucose meters incorporated to assist with pre-meal insulin dosing for patients using basal/bolus insulin regimens other than pumps (insulin syringes, pens or spring-loaded insulin delivery devices such as the V-Go ${ }^{\circledR}$ ). With the increasing use of smart phone technology to support diabetes selfmanagement it is only a matter of time before applications with ABCs are incorporated into them. ${ }^{7}$ This article reviews the current use of
ABCs to calculate insulin dosages and discusses the potential future software innovations which could hopefully help healthcare providers and their patients more safely achieve intensive glucose control and improve disease outcomes.

\section{Barriers to Intensive Glucose Control}

There are multiple barriers facing patients with diabetes and their healthcare providers as they attempt to achieve optimal glucose control. First, hypoglycemia and/or fear of hypoglycemia are the major limiting factors to intensive glucose control, ${ }^{8,9}$ for patients, their families, and healthcare providers. In reality, less than $50 \%$ of patients with diabetes achieve target glucose or glycated hemoglobin $\left(\mathrm{HbA}_{1 \mathrm{C}}\right)$ levels and less than $30 \%$ of patients who take diabetes medications reach recommended target levels. ${ }^{10}$ From a patient's perspective, additional barriers range from the cost of medications, durable medical products, and medical care, to the complexity and time requirements of intensive self-management, social time demands, and, in some cases, the lack of family support or personal motivation..$^{11,12}$ From a provider's perspective, the time requirements (and lack of reimbursement) to analyse voluminous glucose records (data overload) and make frequent insulin or medication adjustments during and also between office visits are significant barriers to intensive management. ${ }^{13,14}$ This has been called the clinical inertia of diabetes care..$^{15}$

\section{Basics of Meal Bolus Calculators}

Insulin meal bolus calculators have been shown to improve postprandial glucose control, reduce dosing errors, allay fears of hypoglycemia, and 
improve confidence in self-management in individuals with diabetes of all ages that use them. ${ }^{16-20}$ Meal bolus insulin dose calculations are based on [1] the target blood glucose level, [2] the current glucose level, [3] the carbohydrate-to-insulin ratio (CIR), [4] total grams of carbohydrate $(\mathrm{CHO})$ to be consumed in the meal, and [5] an insulin sensitivity factor (ISF) (see Table 1). Each of these factors is different for each patient and each must be determined and individualized by the provider for each patient based on frequent glucose testing and insulin adjustments over time. Built into most $A B C$ algorithms is also an insulin correction algorithm designed to adjust the bolus dose additionally for pre-meal glucose levels which are out of the patient's target range (either high or low glucose levels). The correction algorithm automatically adds or subtracts insulin from the meal bolus calculation based on the pre-meal glucose level when it is out of target range. This same insulin correction algorithm can also be used to correct glucose levels anytime they are above a given target range. ABCs used by insulin pumps also factor in the active 'insulin on board' (IOB), which includes the basal insulin continuously being infused as well as the insulin remaining from previous insulin boluses. These IOB insulin correction adjustments are based on mathematical modeling of insulin kinetics for insulin that is injected subcutaneously. ${ }^{21-23}$ The IOB estimations are to prevent the 'stacking' of multiple insulin boluses that can result in hypoglycemia. ${ }^{24}$ Finally, the shape of a bolus infusion can be varied to adjust for the composition of the food (glycemic index) or the duration of a particular meal (e.g. three courses versus seven). ${ }^{25}$ The most common bolus forms are the standard single wave, an extended dual wave, and an extended square wave bolus ${ }^{26,27}$ and are exhibited in Figure 1. Using advanced computer algorithms, the bolus may also be reduced by a temporal amount to prevent hypoglycemia. ${ }^{26,28} \mathrm{~A}$ recent meta-analysis review of six papers including 354 patients revealed less -frequent hypoglycemia, better postprandial glucose controls, good patient acceptance, and satisfaction but no real improvement in $\mathrm{HbA}_{1 \mathrm{c}}$ levels. ${ }^{18}$ The use of $\mathrm{ABCs}$ is now widely accepted by patients and has been shown to contribute to improved glucose contro| ${ }^{18,29}$ and reduced glycemic variability. 19,30,31

\section{Implications of Expanded Use of Automated Bolus Calculators in Glucose Meters (and Smart Phones) to the General Diabetes Population}

The incorporation of ABCs into standard glucose meters (e.g. ACCUCHEK Aviva Expert and Freestyle InsuLinx Blood Glucose Monitoring System) has been intended to assist patients not on insulin pumps but who are using basal/bolus insulin regimens with pre-meal insulin dosing. Early studies on the effectiveness and patient acceptance of their use have been very favourably reported ${ }^{31,32}$ and reviewed. ${ }^{13,33}$ Expanding the use of meters (and smart phone applications) with embedded ABCs to the general diabetes population will increase access to these automated dosing algorithms and should help overcome two major barriers to intensive glucose control in this large population of patients: low numeracy skills and the time requirements for intensive self-management.? Low numeracy skills are common in patients with diabetes $^{34}$ and often result in difficulty reading and understanding nutrition labels, ${ }^{35}$ counting calories and carbohydrates, and calculating insulin bolus doses, ${ }^{35}$ thus contributing to poor glycemic control. ${ }^{34,36}$ The meter-embedded ABCs can help to mitigate this problem, especially if coupled with smart phone nutrition applications for reading food labels and counting calories and carbohydrates (as of June 2013 there were

\section{Table 1: Components of Current Automated Bolus Calculators}

$\begin{array}{ll}\text { Factors Considered } & \text { Factors Not Considered } \\ \text { - Target glucose level } & \text { - Glycemic index of meal } \\ \text { - } \text { Current glucose level } & \text { - Effect of fat and protein content of } \\ \text { - Insulin-carbohydrate ratio } & \text { a mixed meal on rates of nutrient } \\ \text { - Active insulin on board } & \text { absorption and glucose excursions } \\ \text { - Grams of carbohydrate } & \text { - Variable rates of gastric emptying } \\ \text { - Insulin sensitivity factor } & \text { - Variable rates of insulin absorption } \\ & \text { depending on injection site } \\ & \text { - Life-event impact on post-meal excursions }\end{array}$

Figure 1: Typical Meal Bolus Patterns
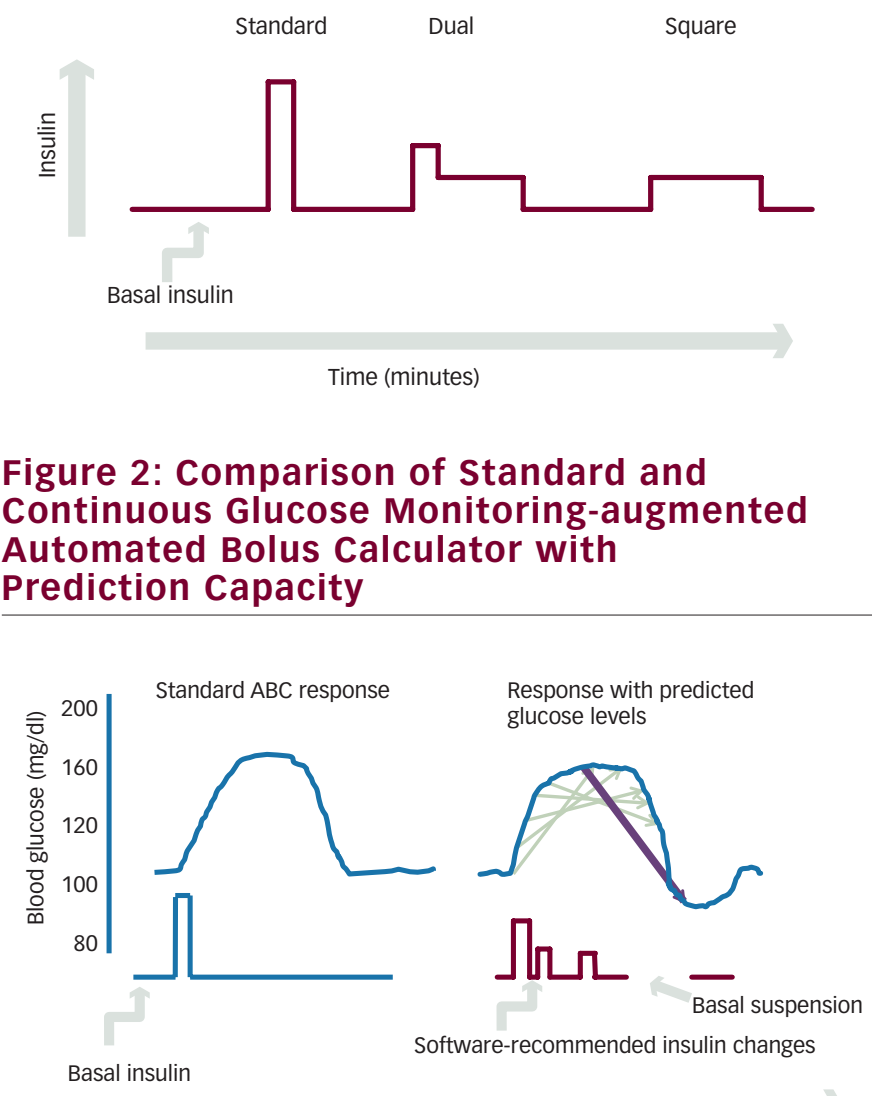

Time (minutes)

$A B C=$ automated bolus calculator

at least 84 such applications featured in the Apple iTunes ${ }^{\circledR}$ Store). The meter-embedded bolus advisors are also effective at overcoming fear of hypoglycemia, increasing confidence in meal-time insulin dosing, and improving glucose control and they are considered easy to use and are associated with high patient satisfaction. .7,28 $^{2}$ Potential time savings, while likely, are not as clear cut, as the time required to use the new technology is significant. The use of $A B C$ embedded glucose meters is a positive development and the potential benefit of their general use in large numbers of patients with both type 1 and type 2 diabetes to improve self-management and overcome clinical inertia is exciting. 
However, their expanded use will require additional individual patient diabetes education about meal calorie and carbohydrate counting so that the information fed into these algorithms is accurate.

\section{Limitations of Current Meal Bolus Insulin Algorithms}

The major difficulties with current insulin dosing algorithms are: (1) they require accurate carbohydrate counting for each meal, which is a major source of inaccuracy in the entire system; ${ }^{37,38}$ (2) they are based primarily on the carbohydrate content of food rather than factoring in the glycemic index of the carbohydrates or the effects of fat and protein content in a meal; and (3) they require considerable calibration based on empirical observation of each individual patient, which still remains labour intensive for both the patient and healthcare provider. For example, dietary fat and fatty acids in meals can delay gastric emptying, 39,40 increase hepatic glucose production, ${ }^{41}$ and increase peripheral insulin resistance, ${ }^{42}$ all potentially contributing to higher postprandial glucose levels. ${ }^{43}$ In addition, there are individual differences in rates of gastric emptying, rates of nutrient absorption, rates of insulin absorption (site, ambient temperature, etc.), as well as differences in tissue sensitivity to the absorbed insulin, which can also vary in the same individual from day to day. The second difficulty lies in having to iteratively refine the values of the carbohydrate-to-insulin ratio and insulin sensitivity factor through trial and error for each patient in order to achieve accurate dosing. We believe that the incorporation of case-based reasoning software into these algorithms will enhance the patient-specificity of ABCs by 'remembering' the effects of different meal components on postprandial glucose excursions. ${ }^{14,44}$

\section{What About Automated Basal Insulin Algorithms?}

Basal insulin algorithms are also commonly used in the management of both type $1^{45,46}$ and type 2 diabetes. ${ }^{47-49}$ Basal insulin algorithms are indicated whenever patients are being converted to basal bolus regimens or demonstrate chronic morning hyperglycemia. The most common approach is to increase the nighttime dose of glargine [rDNA origin] or insulin detemir [rDNA origin] by $2-3$ units every $4-5$ days if the fasting glucose level is greater than $180 \mathrm{mg} / \mathrm{dl}$ until the fasting glucose level is between $120-150 \mathrm{mg} / \mathrm{dl}$, then only increase the basal insulin by 1-2 units every $4-5$ days until fasting glucose level is between 100 and $120 \mathrm{mg} / \mathrm{dl}$. At present, there are no meters or smart phone applications with automated basal insulin algorithms for individual patient use.

\section{Future Approaches to Automated Decision Support Software for Diabetes Management}

The current status of bolus calculator decision support software was also recently reviewed by David Klonoff.50 We believe that decision support software can potentially be expanded to all phases of diabetes insulin dosage advice, including both bolus and basal insulin adjustments. 'sensoraugmented insulin pumps ${ }^{\prime 51,52}$ using CGM-based algorithms have been shown to improve postprandial glycemia both in silico and clinically compared with standard $\mathrm{ABCs} .{ }^{53}$ However, even the most sophisticated permutation of these controllers, the 'iBolus,' cannot yet overcome the unpredictability of individual glycemic responses. ${ }^{53}$ The continued development of a fully integrated closed-loop artificial pancreas is progressing rapidly with improvements in the computer controller algorithms, remote monitoring, and control capacity and size of the devices, which is really exciting as well; ${ }^{54-56}$ however, postprandial glucose control is still a major challenge in these systems. This is not surprising, given our experience with case-based reasoning software to develop the 4 Diabetes Support System ${ }^{\text {TM }}$ (4DSS), where we have observed that individual patients with type 1 diabetes on insulin pumps typically have unique, but consistent, glycemic responses to meals of similar composition. ${ }^{14,57}$ Incorporating 'learned or remembered' individual glycemic responses to previous meals could potentially improve sensor augmented ABC algorithms. We are currently using machine learning techniques (similar to those used to predict the stock market) attempting to predict future glucose levels 30-60 minutes beyond a current CGM value based on the individual's past CGM data. Figure 2 illustrates how sensor augmented insulin pump controllers capable of predicting future glucose excursions (30-60 minutes in advance) could help modulate an insulin pump bolus algorithm as well as suspend the pump for a predicted hypoglycemic reaction.

In addition to automated meal bolus algorithms (ABCS), devices which automate glucose pattern analysis are also in development. ${ }^{57,58}$ For example, Lifescan OneTouch Verio IQ ${ }^{\circledR}$ glucose meter alerts patients and/or healthcare providers about abnormal patterns of glucose control (e.g. high- or low-glucose levels in AM). This is the first commercial device which facilitates self-assessment of abnormal glucose patterns; however, there are no automated basal or bolus dosage suggestions on the device. The 4DSS TM is designed to scan large volumes of insulin pump, CGM, and life-event data, detect recurrent problems of glycemic control and indicate potential causes. ${ }^{52}$ since it also 'remembers' recurrent individual problems for each patient, we are currently trying to automate patient-specific reminders for different life-events (meals, exercise, etc.)

\section{Conclusions}

Technology is rapidly transforming our capacity to help manage patients with diabetes. ABCs are widely accepted by physicians and their patients who are in intensive treatment programs with insulin pumps. ${ }^{18,29}$ Expanded use of this technology to glucose meters and smart phone applications for use in the general diabetes population and all forms of diabetes is possible and could be implemented with enhanced provider and patient education. If we are to overcome the clinical inertia of our current diabetes management, this new technology should be adopted as soon as possible. Within the nearterm, our capacity to monitor insulin pump data, CGM output, and the lifeevents data of our patients remotely and essentially 'live' via smart phones and the cloud will be a reality. We look forward to additional advances in automated bolus and basal insulin dosage calculators, as well as automated glucose pattern analysis, to further enhance diabetes management and improve patient outcomes and quality of life.

\footnotetext{
. Nathan DM, The rationale for glucose control in diabetes mellitus, Endocrinol Metab Clin North Am, 1992;21:221-35.

2. The Diabetes Control and Complication Group, The effect of intensive treatment of diabetes on the developement and progression of long-term complications in insulin dependent diabetes mellitus, N Engl J Med, 1993;329:977-866.

3. The Diabetes Control and Complications Trial: The effect of intensive treatment on progression of diabetic retinopathy
}

in insulin dependent diabetes mellitus, Arch Opthalmol, 1995;113:113-336.

4. Microalbuminuria Collaborative Study Group, United Kingdom, Intensive therapy and progression to clinical albuminuria in patients with insulin dependent diabetes mellitus and microalbuminuria, BMJ, 1995:311:973-7.

5. Gross TM, Kayne D, King A, et al., A bolus calculator is an effective means of controlling postprandial glycemia in patients on insulin pump therapy, Diabetes Technol Ther, 2003;5:365-9. 6. Zisser H, Robinson L, Bevier W, et al., Bolus calculator: a review of four "smart" insulin pumps, Diabetes Technol Ther, 2008;10:441-4. Ceimins EC, Sorli E, An analysis of data management tools for diabetes management: can smart phone technology keep up? J Diabetes Sci Technol, 2010: 6:958-60.

8. Cryer PE, Hypoglycemia: still the limiting factor in the glycemic management of diabetes, Endocr Pract, 2008;14: 750-56. 
9. Cryer $\mathrm{PE}$, The barrier of hypoglycemia in diabetes, Diabetes, 2008; 57:3169-76.

10. Ali MK, Bullard KM, Saaddine JB, et al., Achievement of goals in U.S. diabetes care, 1999-2010, N Eng/ J Med, 2013;368:1613-24.

11. Grant RW, Meigs JB, Overcoming barriers to evidence-based diabetes care, Curr Diabetes Rev, 2006:2:261-9.

12. Nam S, Chesla C, Stotts NA, et al., Barriers to diabetes management: patient and provider factors, Diabetes Res Clin Pract, 2011;93:1-9.

13. Schwartz FL, Guo A, Marling CR, Shubrook JH, Analysis of use of an automated bolus calculator reduces fear of hypoglycemia and improves confidence in dosage accuracy in type 1 diabetes mellitus patients treated with multiple daily insulin injections, J Diabetes Sci Technol, 2012;6:150-2.

14. Schwartz FL, Shubrook JH, Marling CR, Use of case-based reasoning to enhance intensive management of patients on insulin pump therapy, J Diabetes Sci Technol, 2008;2:603-11.

15. Phillips LS, Branch WT, Cook CB, et al., Clinical inertia, Ann Intern Med, 2001;135:825-34.

16. Shashaj B, Busetto E, Sulli N, Benefits of a bolus calculator in pre- and postprandial glycaemic control and meal flexibility of paediatric patients using continuous subcutaneous insulin infusion (CSII), Diabet Med, 2008:25:1036-42.

17. Glaser NS, Iden SB, Green-Burgeson D, et al., Benefits of an insulin dosage calculation device for adolescents with type 1 diabetes mellitus, J Pediatr Endocrinol Metab, 2004;17:1641-51.

18. Ramotowska A, Golicki D, Dzygalo K, Szypowska A, The effect of using the insulin pump bolus calculator compared to standard insulin dosage calculations in patients with type 1 diabetes mellitus - systematic review, Exp Clin Endocrinol Diabetes, 2013:121:248-54.

19. Blazik M, Pankowska E, The effect of bolus and food calculator Diabetics on glucose variability in children with type 1 diabetes treated with insulin pump: the results of RCT, Pediatr Diabetes 2012; 13: 534-9.

20. Schmidt S, Meldgaard M, Serifovski N, et al., Use of an automated bolus calculator in MDI-treated type 1 diabetes: the BolusCal Study a randomized controlled pilot study, Diabetes Care, 2012:35:984-90.

21. Steil GM, Reifman J, Mathematical modeling research to support the development of automated insulin-delivery systems, J Diabetes Sci Technol, 2009;3:388-95

22. Wilinska ME, Chassin $L$, Schaller HC, et al., Insulin kinetics in type-I diabetes: continuous and bolus delivery of rapid acting insulin, IEEE Trans Biomed Eng, 2005;52:3-12.

23. Percival MW, Bevier WC, Wang Y, et al., Modeling the effects of subcutaneous insulin administration and carbohydrate consumption on blood glucose, I Diabetes Sci Technol, 2010:4:1214-28.

24. Bequette BW, Glucose clamp algorithms and insulin time-action profiles, I Diabetes Sci Technol, 2009;3:1005-13.

25. Walsh JAR, ed, Pumping Insulin, Torry Pines Press: San Diego, CA, 2013

26. Chase HP, Saib SZ, MacKenzie T, et al., Post-prandial glucose excursions following four methods of bolus insulin administration in subjects with type 1 diabetes, Diabet Med, 2002;19:317-21.
27. Walsh J, Roberts R, Bailey T, Guidelines for optimal bolus calculator settings in adults, J Diabetes Sci Technol, 2011;5:129-35.

28. Revert A, Calm R, Vehi J, Bondia J, Calculation of the best basalbolus combination for postprandial glucose control in insulin pump therapy IEEE Trans Biomed Eng 2011:58.274-281.

29. Enander R, Gundevall C, Stromgren A, et al., Carbohydrate counting with a bolus calculator improves post-prandial blood glucose levels in children and adolescents with type 1 diabetes using insulin pumps, Pediatr Diabetes, 2012;13:545-51.

30. Lepore G, Dodesini AR, Nosari I, et al., Bolus calculator improves long-term metabolic control and reduces glucose variability in pump-treated patients with Type 1 diabetes, Nutr Metab Cardiovasc Dis, 2012; 22:e15-16.

31. Colin IM, Paris I, Glucose meters with built-in automated bolus calculator: gadget or real value for insulin-treated diabetic patients?, Diabetes Ther, 2013;4:1-11.

32. Sussman A, Taylor EJ, Patel M, et al., Performance of a glucose meter with a built-in automated bolus calculator versus manual bolus calculation in insulin-using subjects, J Diabetes Sci Technol, 2012;6:339-44.

33. Rossetti P, Vehi J, Revert A, et al., Commentary on "Performance of a glucose meter with a built-in automated bolus calculator versus manual bolus calculation in insulin-using subjects" J Diabetes Sci Technol, 2012;6:345-7.

34. Cavanaugh $\mathrm{K}$, Huizinga MM, Wallston KA, et al., Association of numeracy and diabetes control, Ann Intern Med, 2008;148:737-46.

35. Rothman RL, Housam R, Weiss $\mathrm{H}$, et al., Patient understanding of food labels: the role of literacy and numeracy, Am J Prev Med, 2006;31:391-8.

36. Huizinga MM, Elasy TA, Wallston KA, et al., Development and validation of the Diabetes Numeracy Test (DNT), BMC Health Serv Res, 2006;8:96

37. Spiegel G, Bortsov A, Bishop FK, et al.,Randomized nutrition education intervention to improve carbohydrate counting in adolescents with type 1 diabetes study: is more intensive education needed?, J Acad Nutr Diet, 2012;112:1736-46.

38. Brazeau AS, Mircescu H, Desjardins K, et al., Carbohydrate counting accuracy and blood glucose variability in adults with type 1 diabetes, Diabetes Res Clin Pract, 2013:99:19-23.

39. Lodefalk M, Aman J, Bang P, et al.. Effects of fat supplementation on glycaemic response and gastric emptying in adolescents with Type 1 diabetes, Diabet Med, 2008;25:1030-5.

40. Gentilcore $\mathrm{D}$, Chaikomin R, Jones KL, et al., Effects of fat on gastric emptying of and the glycemic, insulin, and incretin responses to a carbohydrate meal in type 2 diabetes, J Clin Endocrinol Metab, 2006;91:2062-7.

41. Rebrin K, Steil GM, Mittelman SD, Bergman RN, Causal linkage between insulin suppression of lipolysis and suppression of liver glucose output in dogs, J Clin Invest, 1996;98:741-9.

42. Bajaj M, Suraamornkul S, Kashyap S, et al., Sustained reduction in plasma free fatty acid concentration improves insulin action without altering plasma adipocytokine levels in subjects with strong family history of type 2 diabetes, I Clin Endocrinol Metab, 2004;89:4649-55.

43. Wolpert HA, Atakov-Castillo A, Smith SA, Steil GM, Dietary fat acutely increases glucose concentrations and insulin requirements in patients with type 1 diabetes: implications for carbohydrate-based bolus dose calculation and intensive diabetes management, Diabetes Care, 2013;36:810-6.

44. Marling C, Shubrook J, Miller W, et al., Intelligent decision support software for Type 1 diabetics on insulin pump therapy presented at the American Diabetes Association 67th Scientific Sessions, June 22-26, 2007, Chicago, IL, US, PO 2087.

45. Gomis R, Storms F, Conget I, et al., Improving metabolic contro in sub-optimally controlled subjects with Type 1 diabetes: comparison of two treatment algorithms using insulin glargine Diabetes Res Clin Pract, 2007;77:84-91.

46. Skyler JS, Skyler DL, Seigler DE, O'Sullivan MJ, Algorithms for adjustment of insulin dosage by patients who monitor blood glucose, Diabetes Care, 1981:4:311-8.

47. Riddle MC, Rosenstock J, Gerich J, The treat-to-target trial: randomized addition of glargine or human NPH insulin to oral therapy of type 2 diabetic patients, Diabetes Care, 2003;26:3080-6.

48. Yki-Jarvinen $\mathrm{H}$, Kauppinen-Makelin R, Tiikkainen $\mathrm{M}$, Insulin glargine or NPH combined with metformin in type 2 diabetes: the LANMET study, Diabetologia, 2006:49:442-51.

49. Davies M, Storms F, Shutler $\mathrm{S}$, et al., Improvement of glycemic control in subjects with poorly controlled type 2 diabetes: comparison of two treatment algorithms using insulin glargine, Diabetes Care, 2005;28:1282-8.

50. Klonoff DC, The current status of bolus calculator decisionsupport software, I Diabetes Sci Technol, 2012;6:990-94.

51. Bergenstal RM, Tamborlane WV, Ahmann A, Effectiveness of sensor-augmented insulin-pump therapy in type 1 diabetes, N Eng/ I Med, 2010;363:311-20.

52. Halvorson $\mathrm{M}$, Carpenter $\mathrm{S}$, Kaiserman $\mathrm{K}$, Kaufman $\mathrm{FR}$ A pilot trial in pediatrics with the sensor-augmented pump: combining real-time continuous glucose monitoring with the insulin pump, J Pediatr, 2007;150:103-105 e101.

53. Rossetti P, Ampudia-Blasco FJ, Laguna A, et al., Evaluation of a novel continuous glucose monitoring-based method for mealtime insulin dosing - the iBolus-in subjects with type 1 diabetes using continuous subcutaneous insulin infusion therapy: a randomized controlled trial, Diabetes Technol Ther, 2012;14:1043-52

54. Breton $\mathrm{M}$, Farret $\mathrm{A}$, Bruttomesso $\mathrm{D}$, et al., Fully integrated artificial pancreas in type 1 diabetes: modular closed-loop glucose contro maintains near normoglycemia, Diabetes, 2012;61:2230-37.

55. Beck RW, Calhoun P, Kollman C, Challenges for outpatient closed loop studies: how to assess efficacy, Diabetes Technol Ther, 2013:15:1-3.

56. Kovatchev BP, Renard E, Cobelli C, et al., Feasibility of outpatien fully integrated closed-loop control: first studies of wearable artificial pancreas, Diabetes Care, 2013:36:1851-8.

57. Schwartz FL, Vernier SJ, Shubrook JH, Marling CR, Evaluating the automated blood glucose pattern detection and case-retrieval modules of the 4 Diabetes Support System J Diabetes Sci Technol, 2010;4:1563-9.

58. Katz LB, Dirani RG, Li G, et al., Automated glycemic pattern analysis can improve health care professional efficiency and accuracy, J Diabetes Sci Technol, 2013;7:163-6. 